\title{
On the Second Major Reform of European Court of Human Rights
}

\author{
Taixia SHEN \\ Law School/Intellectual Property School \\ Jinan University \\ Guangzhou, China \\ Sunbird726@hotmail.com
}

\begin{abstract}
This paper studies the second major reform of the European Court of Human Rights, which was mainly brought about by the entry into force of Protocol No. 14 to the European Convention of Human Rights. It firstly analyses the main contents of Protocol No. 14, then compares the statistics around the implementation of this Protocol. The statistics show that the new judicial formations introduced by this Protocol are effective in reducing the number of pending applications and in improving the filtering ability of applications by the Court. The new admissibility criterion should be studied after its application by the single-judge and the three-judge committee. In conclusion, the second major reform of European Court of Human Rights is useful and meaningful.
\end{abstract}

Keywords-filtering capacity of applications; European Court of Human Rights; European Convention on Human Rights; Protocol No. 14; admissibility criterion

\section{INTRODUCTION}

The European Court of Human Rights (hereafter referred to as the Court) is overwhelmed by the increasing applications; the filtering capacity of applications by the Court is reduced because of a large number of applications. The Court launched reforms to solve this problem. The most recent reform through Protocol No. 14 to the European Convention of Human Rights (hereinafter referred to as Protocol No.14) is under implementation. With this second major reform, the Court focuses on the development of the filtering capacity of applications by the Court as the largest part of individual applications are declared inadmissible or struck out of the Court's list of cases.

There are some researches related to the new procedures introduced by Protocol No. 14. For example, Salerno. F studies the main contents of new procedures before the Court after Protocol No. 14 in his works[1]; Harvey, C. and M. A. Beernaert also introduce the new procedures, and forecasts the future of the court in their article[2]. However, little works look for the implementation of Protocol No. 14 and its influences.

This paper not only presents the main contents of this major reform, but also studies its result. The research on the result of this reform will fill a need academically, and have a practical value. The Court and the Council of Europe can follow their train of thought and strategy of reform if the new measures introduced by Protocol No.14 are effective to improve the filtering capacity of applications, and they have to adjust the strategy if this major reform can't solve the filtering problems of the Court.

In the following part of this paper, it firstly outlines the main contents of Protocol No.14, and then it studies the implementation effect of this Protocol. After reviewing the contents and the implementation effect of Protocol 14, it makes the conclusion.

\section{MAIN CONTENTS OF PROTOCOL NO.14}

According to the composition of applications before the Court, more than 90\% are inadmissible. In 2003, 17,270 applications were declared inadmissible or struck out by the Court, it takes $96 \%$ of the whole cases, only $4 \%$ of the cases were declared admissible[3]. Protocol No. 14 is not intended to make fundamental changes to the system established by the European Convention of Human Rights(hereinafter referred to as the Convention), but to improve its flexibility and efficiency. On the one hand, the Court has to filter the applications more rapidly and effectively within the limited resources, on the other hand, it tries to optimize the resources for dealing with the most important applications that require further examination.

To simplify the proceedings and improve the efficiency of the Court, the main changes made by Protocol No. 14 are as follows:

\section{A. New Judicial Formations}

The Court created "single-judge" as a new judicial formation. Pursuant to the Articles 4, 6, 7 of Protocol No. 14, the "single-judge" may declare an individual application inadmissible or struck it out where such decision can be taken without further examination. In addition, in order to protect judicial impartiality, the "single-judge" is assisted by the rapporteurs who shall function under the authority of the President of the Court, they are part of the Registry of the Court. The capacity of three-judge committee is enlarged, it is responsible for filtering the repetitive applications.

\section{B. New Admissibility Criterion}

A new admissibility criterion is added to the criteria specified in the paragraph 3 of Article 35 of the Convention to raise the threshold of admissibility. This amendment allows the Court to concentrate more time and resources to the cases 
that need a further examination. The new admissibility criterion includes two aspects:

\section{1) Inadmissible}

The Court may declare an individual application inadmissible for the reason that the applicant has not suffered a significant disadvantage;

\section{2) Admissible}

The Court may declare an individual application admissible even if the applicant has not suffered a significant disadvantage.

a) As a result of compliance with human rights guaranteed by the Convention and the Protocols thereto requires an examination of the application on the merits,

b) Provided that the case has not been duly considered by a domestic tribunal.

For a period of two years following the entry into force of the protocol No. 14, only the chambers and the grand chamber of the Court may apply the new admissibility criterion. Protocol No. 15 to the European Convention of Human Rights deletes the words "and provided that no case may be rejected on this ground which has not been duly considered by a domestic tribunal of the sub-paragraph b of Article 35, paragraph 3 of the Convention" and shortens the period of application. There are several criticisms of the new admissibility criterion after its creation, especially from the perspective of the victim; it is interpreted as a limitation of the right of appeal[4].

Besides, some flexible rules such as the third party intervention, the friendly settlement and the enforcement of the investigation power of the Court are used to improve the flexibility of the control system.

\section{IMPLEMENTATION EFFECT OF PROTOCOL NO.14}

The Protocol No. 14 came into force on 1 June, 2010. The statistics before and after the implementation of this Protocol are important to examine its effects and influences. This part compares the statistics round the new reform, especially after the implementation of Protocol No. 14. The amounts of individual applications for certain period and the speed of the filtering are two important criteria to measure the effects of the new measures. This part analyses the statistics of the Court from 1 Jan. 2009 to 31 Dec. 2014.

The changes in the number of new applications assigned to a judicial formation is an important part of the investigation, and the number of applications decided, the number of pending applications may measure the filtering capacity of applications by the Court.

\section{A. Number of New Applications assigned to a Judicial Formation}

In 2010, 61,100 applications were allocated to a judicial formation, an overall increase of $7 \%$ compared to 57,000 in 2009. In 2011, 64,300 applications were allocated to a judicial formation, an increase of $5 \%$ compared to the figure of the previous year. The number of new applications assigned to a judicial formation is 64,900 applications in 2012, the number in 2013 is 65,800 and the number in 2014 is 56,300 [5]. The number of new applications assigned to a judicial formation increased gradually from 2009 to 2013, and it decreased in 2014. That is the first time since 2003 that the number of allocated cases has decreased.

It is clear that the Court still faced the burden of growing applications; approximately 168 applications are allocated to a judicial formation per day in 2010, about 177 applications in 2011, 178 in 2012, 180 in 2013 and 154 in 2014.

\section{B. Change of the Number of Applications decided}

The number of applications changed as follow: In 2009, the total number of applications decided is 35,460, including 33,065 declared inadmissible or struck out by a decision, 2,395 applications were decided by a judgment, while $93 \%$ of applications were decided by a decision. In 2010, the total number of applications decided is 41,183, an increase of $16 \%$ compared to the number of $2009(35,460), 38,576$ applications were declared inadmissible or struck out by a decision and 3,876 applications were decided by a judgment delivered. Of the total number, the number of applications declared inadmissible or struck out by a decision of 2010 increased from $17 \%$ compared to the number of 2009 [6]. In 2011, 50,677 applications were declared inadmissible or struck out by a decision and 1,511 applications were decided by a judgment delivered. Of the total number (52,188 applications decided), the number of applications declared inadmissible or struck out by a decision has increased, while $97 \%$ of applications were delivered by a decision. Comparing the figures of 2011 and 2010, there was a 31\% increase in the number of applications declared inadmissible or struck out by a decision, and also a $27 \%$ increase in the number of applications decided by a judgment delivered. In 2012, the total number of applications decided is 87,879 , an increase of $68 \%$ compared to the number of 2011 (52,188), 86,201 applications were declared inadmissible or struck out by a decision, an increase of $70 \%$ compared to the number of $2011(50,677)$ and 1,678 applications were decided by a judgment delivered, an increase of $11 \%$ compared to the number of $2011(1,511)$ [7]. In 2014, 86,063 applications were disposed of judicially, a decrease of $8 \%$ in relation to 2013 (93,401), 83,675 applications were declared inadmissible or struck out of the list of cases by a Single Judge, a Committee or a Chamber, a 7\% decrease compared with $2013(89,740)$ [8].

The number of applications declared inadmissible or struck out by a decision increased since the implementation of Protocol No. 14(from 2010 to 2013), and there is a decrease since 2014. The new judicial formations work well for filtering the applications, they shared much of the work of the Court, and especially the single-judge has functioned well since its creation.

\section{Change of the Number of pending Applications}

In early 2010, 119,300 applications were pending before a judicial formation, and at the end of this year, pending applications increased by $17 \%$, there were 4,100 applications pending before the three-judge committee, while 88,400 applications were pending before the single-judge [9]. By the end of 2011, the number of pending applications reached up to 151,600 , an increase of $9 \%$ compared to the same period in 2010, however at the end of 2012, the number of pending cases 
has decreased $16 \%$, and it is down to 128,100 . At the end of 2012, there are 25,200 applications were pending before the three-judge committee, and 59,850 applications were still pending before the single-judge [10]. The number of whole pending applications in 2013 is 99,900 and the number in 2014 is 69,900 , it has decreased $30 \%$. There are 26,500 applications were pending before the single-judge formation at the end of 2013, and just 8,200 at the end of 2014 [11].

The pending applications of the Court has declined since 2012, it proves that the new reform of the judicial formations are useful to reduce the number of pending applications and accelerate the filtering efficiency of applications by the Court; However, the Court still faces a heavy burden and that it must continue to accelerate the filtering efficiency.

\section{Implementation Effect of Admissibility Criterion}

The Court developed the "practical guide on admissibility criterion" for implementation of the new admissibility criterion. In June 2012, the Court issued a research report which has analyzed the jurisprudences systematically and synthesized the jurisprudential principles.

According to this report, over the two-year period provided for by Article $20 \S 2$ of Protocol No. 14, the Court's chambers have applied the new admissibility criterion to 26 complaints made under articles 6 and 13 of the Convention and article 1 of Protocol No. 1, with the majority of cases falling under article 6 . The applications affected by the new admissibility criterion can be classified into two categories: these are the cases applying the new admissibility criterion, and cases rejecting the new admissibility criterion. 26 applications are inadmissible in the absence of a "significant disadvantage" due to the application of the new admissibility criteria from 1 June, 2010 to 2012. The new criterion has been considered but rejected by the Court in 16 cases over the two years [12]. However, the reasons to exclude the applications of the new criterion were not clearly explained and systematized.

The Court classified the absence of a "significant disadvantage" in two categories:

1) the absence of a significant financial disadvantage

The amount of money has become a key element to distinguish a lack of financial disadvantage;

2) The absence of a significant non-financial disadvantage

The Court is not exclusively concerned with cases of insignificant financial sums. The actual outcome of a case at national level might have repercussions other than financial ones [13].

The Court has developed some principles of "Whether respect for human rights requires an examination of the case on the merits," these are the cases raising the serious questions concerning the general interest; serious questions concerning the important principle for guiding the national judgments, serious questions affecting the application or the interpretation of the Convention or important questions concerning national law. The clause: "whether the case has been duly considered by a domestic tribunal" was applied in the cases, mainly concerning the alleged breach of the guarantees of Article 6 of the Convention. The Court stated that "As for the interpretation of duly", the new criterion is not to be interpreted as strictly as the requirements of a fair hearing under Article 6 [14].

The Court has developed a standard for distinguishing whether the applicant has suffered a "significant disadvantage" or not. The standard requires that a violation of a right, however real from a purely legal point of view, should attain a minimum level of severity to warrant consideration by an international Court. (Giusti v. Italy, Shefer v. Russia, etc.)

Although the "practical guide on admissibility criterion" has been developed, although the connotation of the new admissibility criterion today with the jurisprudential interpretation is clearer than that of 1 June, 2010 (Protocol No. 14 came into force), the Court still faces difficulties in implementing the new admissibility criterion. The Protocol No. 15 makes some change of the new admissibility criterion.

\section{CONCLUSION}

The Court launched the second major reform since 2004 to strengthen the long-term effectiveness of the control system established by the Convention. It is necessary to develop new measures to improve the filtering capacity of applications because of the difficulties encountered by the Court to deal with the ever increasing applications. The new filtering measures mainly consist of the new judicial formations, the new admissibility criterion and other filtering measures according to the Protocol No.14. The statistics round the implementation of the new measures show that the new judicial formations are effective in reducing the number of pending applications and in improving the filtering ability of applications by the Court.

Since the first two years following the introduction of the new admissibility criterion, the Court has developed the jurisprudential principles relating to the new criterion gradually. It seems that the result of the new admissibility criterion's implementation is positive. However, it must continue to study its effects particularly after its application by the single-judge and the three-judge committee. Till now, there is no enough data to analyze.

In conclusion, the main measures brought by Protocol No.14 are effective in improving the filtering capacity of applications and in enhancing the control system established by the Convention, the result of second major reform is positive, it is the foundation of the following reform of the Court. However, the Court needs further efforts in this direction.

\section{ACKNOWLEDGMENT}

This paper is the research result of the National Social Science Fund Youth Project entitled "Research on judicial protection mechanisms for human rights in Hong Kong Special Administrative Region " (No. 15CFX016). 


\section{REFERENCES}

[1] Salerno, F, Eds. The New Procedure before the European Court of Human Rights after Protocol No. 14(La Nouvellle Procedure devant la Cour Européenne des Droits de l’Homme)(In French). Bruxelles: Bruylant, 2007.

[2] Pascal, D. J. and E. Lambert-Abdelgawad, Eds. What Filtering the Applications by the European Court of Human Rights?(Quel Filtrage des Requêtes par la Cour Européenne des Droits de l'Homme?)(In French).Strasbourg: Council of Europe, 2011.

[3] Council of Europe, "Explanatory Report to Protocol No. 14 to the Convention for the Protection of Human Rights and Fundamental Freedoms, amending the control system of the Convention." Strasbourg:Council of Europe, 2004. [Available at: http://conventions.coe.int/Treaty/EN/Reports/Html/194.htm.Feb. 2012].

[4] Padelletti, M. L., "The new conditions of the admissibility criterion of an individual application: The entity of Damage Summoned by the Victim (les Conditions de Recevabilité Matérielles d'une Requête Individuelle: L’Entité du Préjudice Invoqué par la Victime),” in Salerno, F, Eds. The New Procedure before the European Court of Human Rights after Protocol No. 14(La Nouvellle Procedure devant la Cour Européenne des Droits de l'Homme)(In French). Bruxelles: Bruylant, 2007, p105.

[5] European Court of Human Rights, the ECHR in Facts and Figures-2014, pp3-5, Strasbourg: European Court of Human Rights, 2015.

[6] European Court of Human Rights, Analysis of statistics 2010, pp 4-6, 10, Strasbourg: European Court of Human Rights, 2011.
[7] European Court of Human Rights, Analysis of statistics 2011, pp 4-7, Strasbourg: European Court of Human Rights, 2012.

[8] European Court of Human Rights, Analysis of statistics 2014, pp 4, Strasbourg: European Court of Human Rights, 2015.

[9] European Court of Human Rights, Annual report 2010, pp 145-158, Strasbourg: European Court of Human Rights, 2011.

[10] European Court of Human Rights, Annual report 2011, pp 145-158, Strasbourg: European Court of Human Rights, 2012.

[11] European Court of Human Rights, Analysis of statistics 2014, pp 4, Strasbourg: European Court of Human Rights, 2015.

[12] European Court of Human Rights, Research Report, "The new admissibility criterion under Article $35 \S 3$ (b) of the Convention: caselaw principles two years on ECHR ", Strasbourg: European Court of Human Rights, 2012. [Available at:

http://www.echr.coe.int/NR/rdonlyres/ D4E1DEBF-BC2B-4BB8-93FD2A4956731E0F/0/RAPPORT_RECHERCHE_New_admissibility_cirter ion_EN.pdf. Dec., 2012].

[13] European Court of Human Rights, "Brighton Declaration", p6, Strasbourg: European Court of Human Rights, 2012. [Available at: http://hub.coe.int/en/20120419-brighton-declaration/. Dec., 2012).

[14] European Court of Human Rights, "Brighton Declaration", p9, Strasbourg: European Court of Human Rights, 2012. [Available at: http://hub.coe.int/en/20120419-brighton-declaration/. Dec., 2012). 